\title{
Study of blend composition of nano silica under the influence of neutron flux
}

\author{
Elchin Huseynov*, Adil Garibov and Ravan Mehdiyeva
}

\begin{abstract}
Nano $\mathrm{SiO}_{2}$ compound with $160 \mathrm{~m}^{2} / \mathrm{g}$ specific surface area and $20 \mathrm{~nm}$ sizes has been irradiated continuously with neutron flux up to 20 hours in various periods in TRIGA Mark II type research reactor. The initial activities of different type radionuclides defined in the result of eight day activity analysis changes between wide range of $1,5 \mathrm{kBq}-1,5 \mathrm{GBq}$. In the result of activity analysis carried out after the irradiation, the element content of 0,5\% mixture existing in nano $\mathrm{SiO}_{2}$ compound has been defined with radionuclides of relevant element. It has been defined percentage amounts of elements in blend composition according to the performed activities.
\end{abstract}

PACS: 81.07.Wx; 61.46. + w; 61.80.Hg; 28.20.Fc; 92.20.Td

Keywords: Nanopowder; Nano silica; Nanomaterial; Neutron activation analysis; Neutron irradiation; Radioactivity; Radioisotopes

\section{Introduction}

Silicon and its oxide compositions are widely applied in different fields of science and technology for their unique physical, physical-chemical properties and radiation- durability [1-9]. In real application conditions the surface of silicon-based materials and devices are covered with oxide layer. The influence of the oxide layer formed on surface on physical properties of base material and effective thickness in terms of defence from subsequent oxidation process are usually in nanometer form. On the other hand nano-size silicon and $\mathrm{SiO}_{2}$ are of great importance for their physical and surface physical-chemical properties.

Oxide compositions of silicon are widely used in electronics, radiation technology and radiochemical processes $[1,2,5,9,10]$. Conversion of ionizing radiation energy and transfer to surface levels is of great importance for radiative study of materials and radiation technology. From this point of view nano-size $\mathrm{SiO}_{2}$ is a perspective and at the same time an actual model system for study of radiation defect-formation, conversion and transfer processes of ionizing radiation energy. In recent years formation of nano size $\mathrm{SiO}_{2}$ compound and improvement of their purity degree are in the focus of attention

\footnotetext{
* Correspondence: hus.elchin@yahoo.com

Institute of Radiation Problems of Azerbaijan National Academy of Sciences, AZ 1143, B. Vahabzadeh 9, Baku, Azerbaijan
}

of researchers [11-13]. At modern period the purity degree of nano silica has been brought to $99,5-99,9 \%$ and intensive scientific studies are being carried out in order to increase its value.

In the presented work under the influence of neutrons with $2 \times 10^{13} \mathrm{n} / \mathrm{cm}^{2} \mathrm{~s}$ intensity it has been studied the dependence of activities of radioactive nucleus, formed in the result of neutron flux in powder and extruded shaped, 99,5\% purity, $20 \mathrm{~nm}$ size nano $\mathrm{SiO}_{2}$ compound, on integral dose and decomposition time after irradiation. On the base of the achieved results it has been carried out the quality and quantity identification of blends in the composition of nano $\mathrm{SiO}_{2}$ compound.

The sample used in the presented work is widespread in the nature and met in crystalline forms as quartz, rock crystal, flint, opal, etc. In these crystals silica exists with different percentages and "Obsidian" natural glass has more $\mathrm{SiO}_{2}$ percentage (about $70-75 \%$ of $\mathrm{SiO}_{2}$ ) among natural crystals existing in the nature [14,15]. Nowadays, macro silica is treated with several methods and it was available to obtain maximum macro $\mathrm{SiO}_{2}$ (In Egypt) with 99,85\% purity. However, the synthesis method of high purity $\mathrm{SiO}_{2}$ nanopowder in nanosize differs slightly and in this case, practically obtain of $\mathrm{SiO}_{2}$ nanopowder with perfect purity (100\% purity) is almost

\section{实


impossible [16]. Thus, if purity of nano $\mathrm{SiO}_{2}$ powder obtained before was $75 \%$, at present development of modern technology allowed obtaining $\mathrm{SiO}_{2}$ nanopowder with 99,9\% purity [11-13]. Nowadays, nano $\mathrm{SiO}_{2}$ compounds with $99-99,9 \%$ purity are considered to be high purity nano $\mathrm{SiO}_{2}$ compounds and samples with this purity are of wide application. As it was mentioned before, nano $\mathrm{SiO}_{2}$ compound with $99,5 \%$ purity has been used during the experiment, so it can be considered as a high purity nano $\mathrm{SiO}_{2}$ compound. However, the sample contains $0,5 \%$ of impurities and even if at first sight it can seem a small indicator, it is very large value in nano-scale and molecule compiling. Therefore, if to take into account that there is approximately $10^{22}$ units of particles in atomic level in $1 \mathrm{~g}$ of $\mathrm{SiO}_{2}$ nanopowder, then $0,5 \%$ to be great value (approximately $5 \times 10^{19}$ mixture particle) is obvious. Naturally, 0,5\% mixture doesn't impact the physical parameters of sample, but it clearly manifests itself during irradiation in the reactor and is of great significance.

\section{Methods}

From previous studies it is known that the specific surface area of nanomaterial used in the experiment is $160 \mathrm{~m}^{2} / \mathrm{g}$, dimensions are $20 \mathrm{~nm}$ and some parameters of the used sample has been studied [17-19]. In the presented work the samples have been irradiated by neutron flux $2 \times 10^{13} \mathrm{n} / \mathrm{cm}^{2} \mathrm{~s}$ in central channel (Channel A1) of TRIGA Mark II light water pool type research reactor at full power $(250 \mathrm{~kW})$ in "Reactor Centre" of Jozef Stefan Institute (JSI) in Ljubljana city of Slovenia. It is important to note that the JSI TRIGA reactor has been thoroughly characterized [20-25] and the computational model used for computational characterization has been thoroughly verified and validated [26,27] against several experiments. It should be mentioned that in this channel the parameters of neutron flux at full power mode are $5.107 \times 10^{12} \mathrm{~cm}^{-2} \mathrm{~s}^{-1}\left(1 \pm 0.0008, \mathrm{E}_{\mathrm{n}}<625 \mathrm{eV}\right)$ for thermal neutrons, $6.502 \times 10^{12} \mathrm{~cm}^{-2} \mathrm{~s}^{-1}\left(1 \pm 0.0008, \mathrm{E}_{\mathrm{n}} \sim 625 \mathrm{eV} \div\right.$ $0.1 \mathrm{MeV}$ ) for epithermal neutrons, $7.585 \times 10^{12} \mathrm{~cm}^{-2} \mathrm{~s}^{-1}$ $\left(1 \pm 0.0007, E_{n}>0.1 \mathrm{MeV}\right)$ for fast neutrons and finally for all neutrons the flux density in central channel is $1.920 \times 10^{13} \mathrm{~cm}^{-2} \mathrm{~s}^{-1}(1 \pm 0.0005)[20,26]$.

The powdered nano $\mathrm{SiO}_{2}$ has been irradiated in a special cylindrical aluminium container. Density of powdered nano $\mathrm{SiO}_{2}$ compound is $\rho_{\text {powder }}=0,1 \mathrm{~g} / \mathrm{cm}^{3}$ (density in packaging is approximately $\sim 0,3 \mathrm{~g} / \mathrm{cm}^{3}$ ), volume of the sample in cylinder-shaped radiation packaging is $\mathrm{V}_{\text {powder }} \approx 2,3 \mathrm{~cm}^{3}$, the area of the sample which is exposed to neutron flux is $\mathrm{S}_{\text {powder }} \approx 10 \mathrm{~cm}^{2}$. The sample which is approximately same amount $\sim 0,7 \mathrm{~g}$ being pressed in a special press machine has been put in a special form and its parameters are: $\rho_{\text {tablet }}=$ $2,9 \mathrm{~g} / \mathrm{cm}^{3}, \mathrm{~V}_{\text {tablet }} \approx 0,2 \mathrm{~cm}^{3}, \mathrm{~S}_{\text {tablet }} \approx 1,8 \mathrm{~cm}^{2}$. The prepared experiment sample was irradiated firstly for 5 minutes evaluate the final activity after 20 hour radiation. Then other 8 samples (each one apx. 0,7 g) were divided into 4 groups and each of them irradiated continuously for 5,10 , 15,20 hours by neutron $2 \times 10^{13} \mathrm{~cm}^{-2} \mathrm{~s}^{-1}$ in central channel (Channel A1) of TRIGA Mark II type research reactor at full power $(250 \mathrm{~kW})$. Both forms of the samples (4 powder samples and 4 tablets) have been irradiated in $2 \times 10^{13}$ $\mathrm{n} / \mathrm{cm}^{2} \mathrm{~s}$ intensity of neutron flux. Absorption dose values of the studied samples have been defined according to geometric dimensions of powdered and tablet-formed samples, intensity of irradiation, irradiation periods, density of influencing neutron flux and energy spectra of neutrons. The value of neutron flux for powdered samples is $3,95 \times 10^{18} \div$ $1,58 \times 10^{19}$ and for tablet-formed ones it changes within the neutron range $6,67 \times 10^{17} \div 2,67 \times 10^{18}$. The dependence of neutrons falling on the sample on irradiation period for samples of both types has been given in Figure 1. As it is seen, the interacting neutron flux and thus the amount of absorbed neutrons in powdered sample is approximately 25 times more than in tablet-formed.

Radionuclides being formed in composition of nano $\mathrm{SiO}_{2}$ compound after the interaction with neutron have been analysed in spectrometers "Ortec HPGe detectors (Coaxial, Low and Well-Type)" and "Canberra coaxial HPGe detector". The radioactivity, isotope composition and amount of blend elements of the irradiated samples have been determined on technique [28-31].

\section{Results and discussions}

The main probable process of interaction of neutrons with substance is radiation capacity [28]:

$$
n+{ }^{A} Z \rightarrow{ }^{A+1} Z^{*} \rightarrow{ }^{A+1} Z+\gamma
$$

here ${ }^{A} Z$ - irradiated isotope, ${ }^{A+1} Z^{*}$ - excited nucleus formed as a result of neutron capacity and $\gamma$ - second gamma rays. Radioactive excited samples are formed in the result of the processes shown in irradiated samples. Their identification has been studied with the method of gamma spectroscopy. $\gamma$ - ray intensities appropriate to nuclear transitions in gamma spectra are different depending on irradiation period and decay constants. One of these spectra has been given in Figure 2 as an example.

After neutron irradiation it has been studied the change of samples' activities after 192 hours. It has been determined that initial radioactivities of irradiated samples change between the ranges $1,5 \mathrm{kBq}-1,5 \mathrm{GBq}$ (powder and tablet each one total four sample approximate $3 \mathrm{~g})$. Define of concentrations of elements is conducted on the base of the activities originated in appropriate energy range. The activity is determined on the following formula based on nuclear constants [28]: 


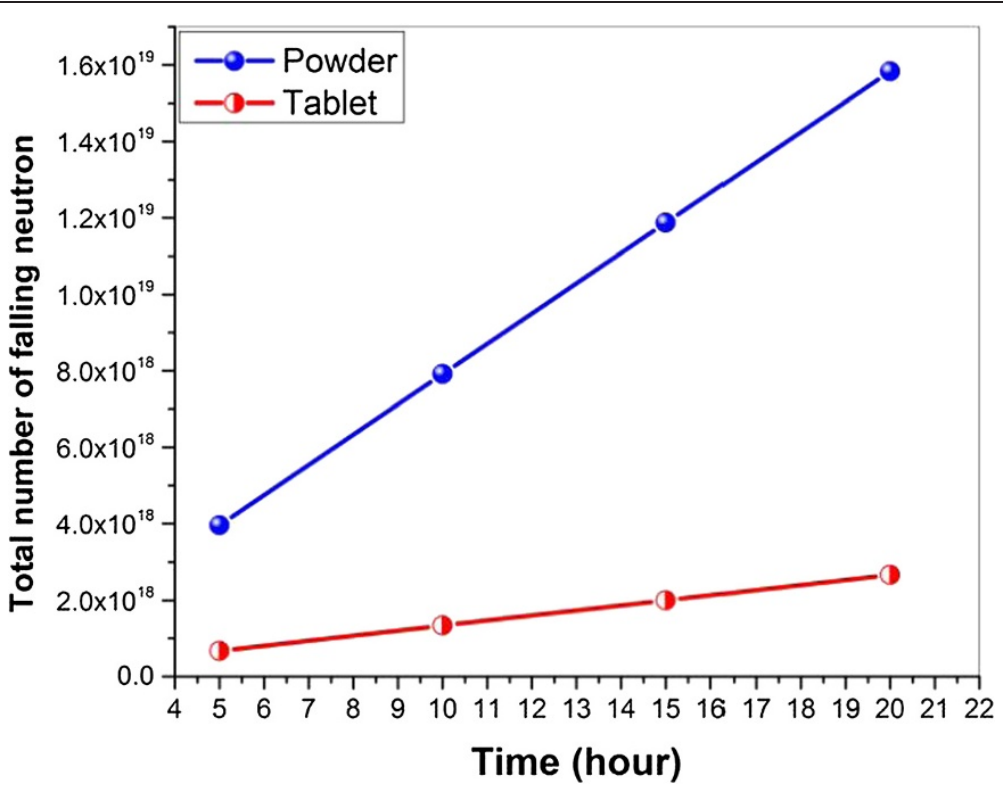

Figure 1 Dependence of neutrons falling on the sample on irradiation period.

$$
\begin{aligned}
& A=\sigma \Phi\left(\frac{m}{M}\right) N_{A} \Theta P_{\gamma} \xi\left(1-\exp \left(-\lambda \tau_{\text {ray }}\right)\right) \times \\
& \left(1-\exp \left(-\lambda \tau_{\text {mes }}\right)\right) \exp \left(-\lambda \tau_{\text {cool }}\right)
\end{aligned}
$$

here, $\mathrm{A}$ - measured activity $(\mathrm{Bq}), \sigma-$ cross section of activation of defined isotopes $\left(\mathrm{cm}^{2}\right), \Phi-$ neutron flux (n/ $\mathrm{cm}^{2} \mathrm{~s}$ ), $\mathrm{m}$ - weight of defined element (g), M - atomic weight of defined element ( $\mathrm{g} / \mathrm{mol}), \mathrm{N}_{\mathrm{A}}$ - Avogadro number $(1 / \mathrm{mol}), \Theta$ - distribution of activated isotope, $\mathrm{P}_{\gamma}-$ distribution probability of $E$ energy gamma quantum, $\xi$ - defect efficiency according to $E$ energy, $\lambda$ - decay constants of the formed isotopes, $\tau_{\text {ray }}, \tau_{\text {mes }}, \tau_{\text {cool }}-$ irradiation,

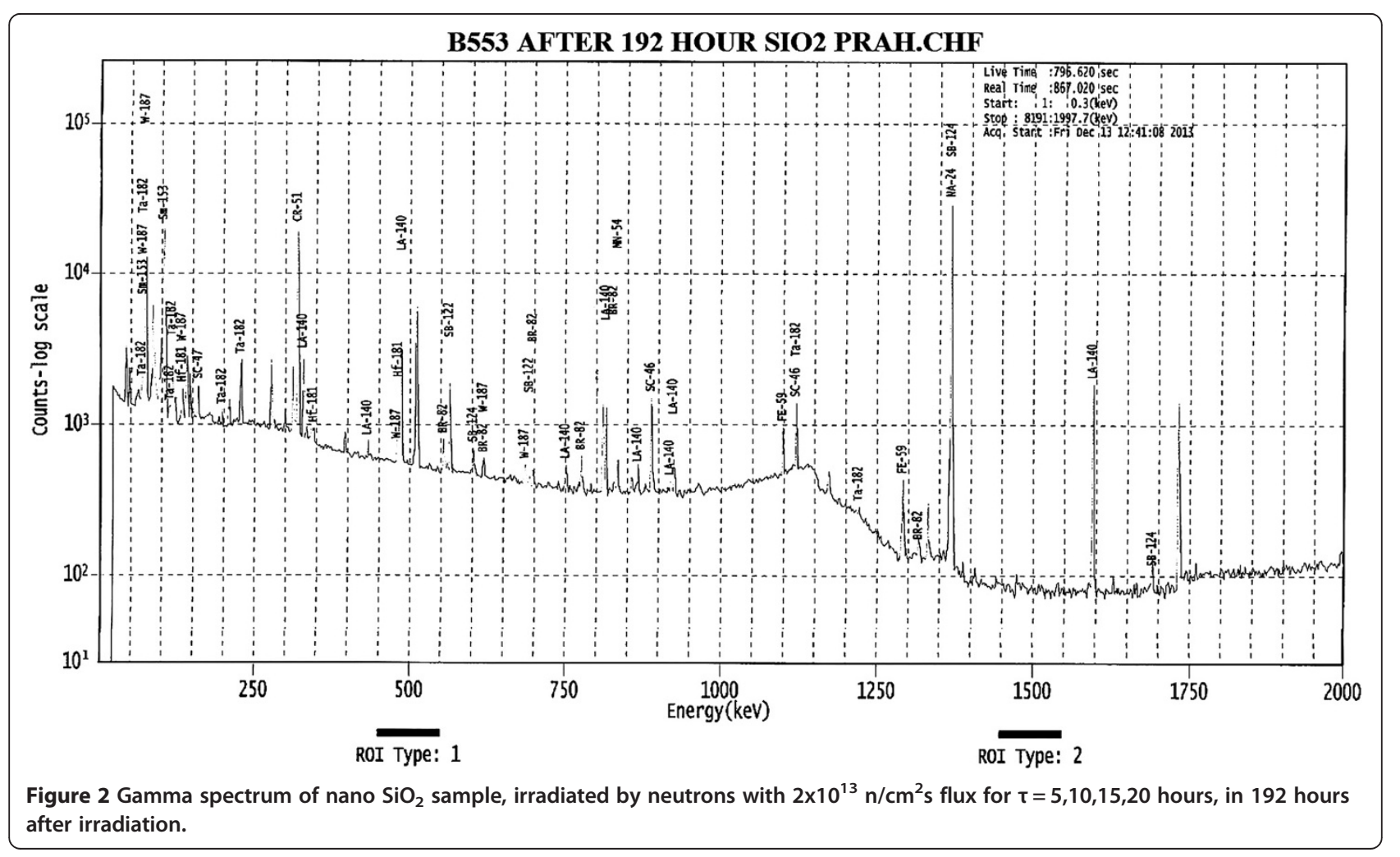


measurement and cooling time interval of samples correspondingly.

Activities of newly formed radioactive isotopes observed in irradiated samples change correspondingly to decay constants. The initial activities of different type radionuclides defined in the result of eight day activity analysis changes between wide range of $1,5 \mathrm{kBq}-1,5 \mathrm{GBq}$. Just for this reason we decided to divide these elements into four groups. The observed radioactive isotopes can be divided conditionally into four groups as $\mathrm{I}-\mathrm{A} \leq 10 \mathrm{kBq}$, II $-\mathrm{A} \leq 100 \mathrm{kBq}$, III $-\mathrm{A} \leq 2 \mathrm{MBq}$ and IV $-\mathrm{A} \leq 1,5 \mathrm{GBq}$ for their activities. Observation time dependence of initial activities of the observed radioactive isotopes on conventional groups has been given in figures. Dependency of radioactivity on observation time has been defined for both powdered and tablet-formed nano $\mathrm{SiO}_{2}$ (Figures 3, 4, 5 and 6). It should be noted that all used graphics cover an eight day- period and elapsed time was denominated in hours. First, let's review radionuclides with activity up to $10 \mathrm{kBq}$ which is generated in nanocompound with the influence of neutron flux (Figure 3).

In general, it has been observed 7 types of radionuclides, thus their half-life changes from 80,4 hours up to 748,2 hours. For living periods, the observed "I group" radionuclides can be lined up as Sc-47 (80,4 hour), Hf-181 (1017,36 hour), Fe-59 (1067,88 hour), Sb-124 (1444,8 hour), Sc-46 (2010,96 hour), Ta-182 (2753,76 hour) and Mn-54 (7489,2 hour).

The activity of radionuclides included inside II group is up to $70 \mathrm{kBq}$ (Figure 4). It has been observed two type $\mathrm{Br}-82$ and $\mathrm{Sb}-122$ radionuclides that their half-life are $35,3 \mathrm{~h}$ for $\mathrm{Br}-82$ and $64,8 \mathrm{~h}$ for $\mathrm{Sb}-122$ respectively. As it is seen from Figure 4, after 8 days the activity of $\mathrm{Br}-82$ isotope decreased approximately down to $5 \mathrm{kBq}$, and the activity of $\mathrm{Sb}-122$ down to $10 \mathrm{kBq}$.

The activity of only one of four radionuclides including to the third group is approximately up to $2 \mathrm{Mbq}$ (for comparison: the activity in tablet form of relevant radionuclide is approximately up to $72 \mathrm{kBq}$, right column in the fig.) and the activity of other three radionuclides do not exceed $0,6 \mathrm{MBq}$ (Figure 5). Half-lifes of observed radionuclides are $24 \mathrm{~h}$ (W-187), 40,32 h (La-140), 46,28 h (Sm-153) and $665 \mathrm{~h}(\mathrm{Cr}-51)$ and after eight days activity for Cr-51 decreased up to approximately $0,5 \mathrm{MBq}$, and $0,1 \mathrm{MBq}$ for other ones.

Only one element is included to the last IV group that its activity was approximately up to $1,5 \mathrm{GBq}$ (for comparison: the activity in tablet form of relevant radionuclide is approximately $54 \mathrm{MBq}$, right column in the fig.). The half-life of observed high activity Na-24 isotope is 14,95 hours and at the end of measurement day the activity of $\mathrm{Na}-24$ isotope decreased approximately down to $0,2 \mathrm{MBq}$ (Figure 6). It can be said that the major part of mixture containing $\mathrm{Na}-24$ isotope which is more active than other ones is the element of $\mathrm{Na}$.

It is seen from the dependency given in Figure 4 that activities of isotopes with small radioactive decay

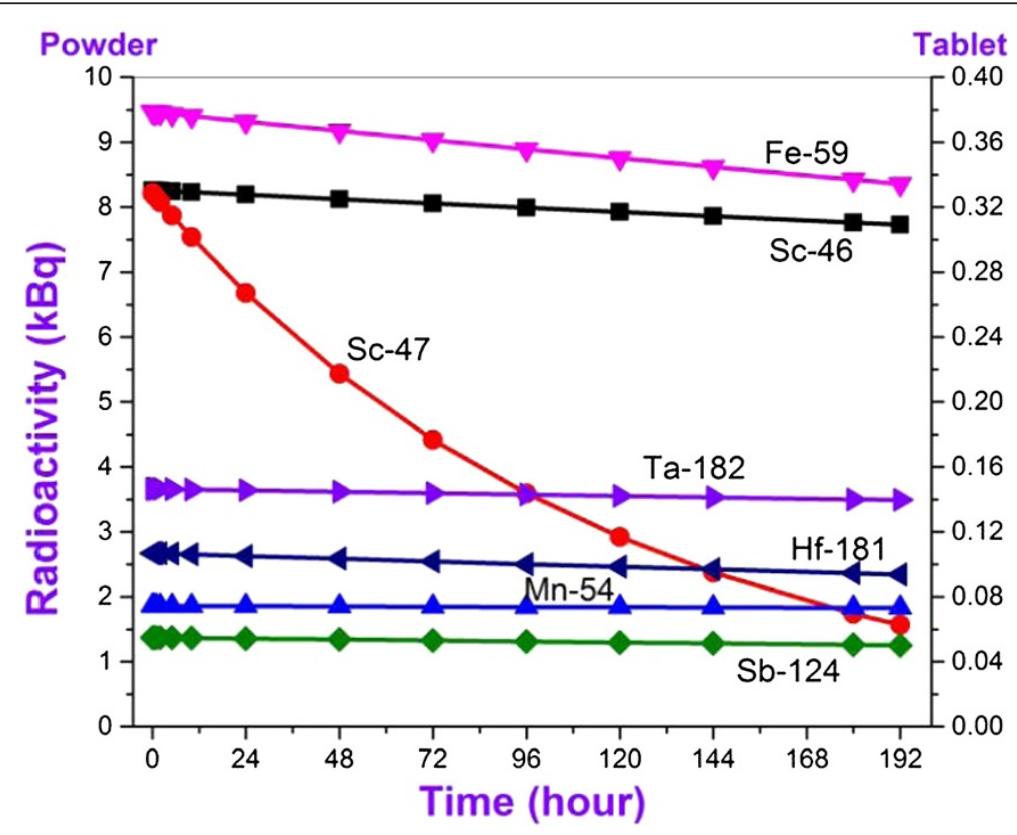

Figure 3 Dependence of activities of conditional I group radionuclides being formed in nano $\mathrm{SiO}_{2}$ under the influence of neutron flux on measurement time. 


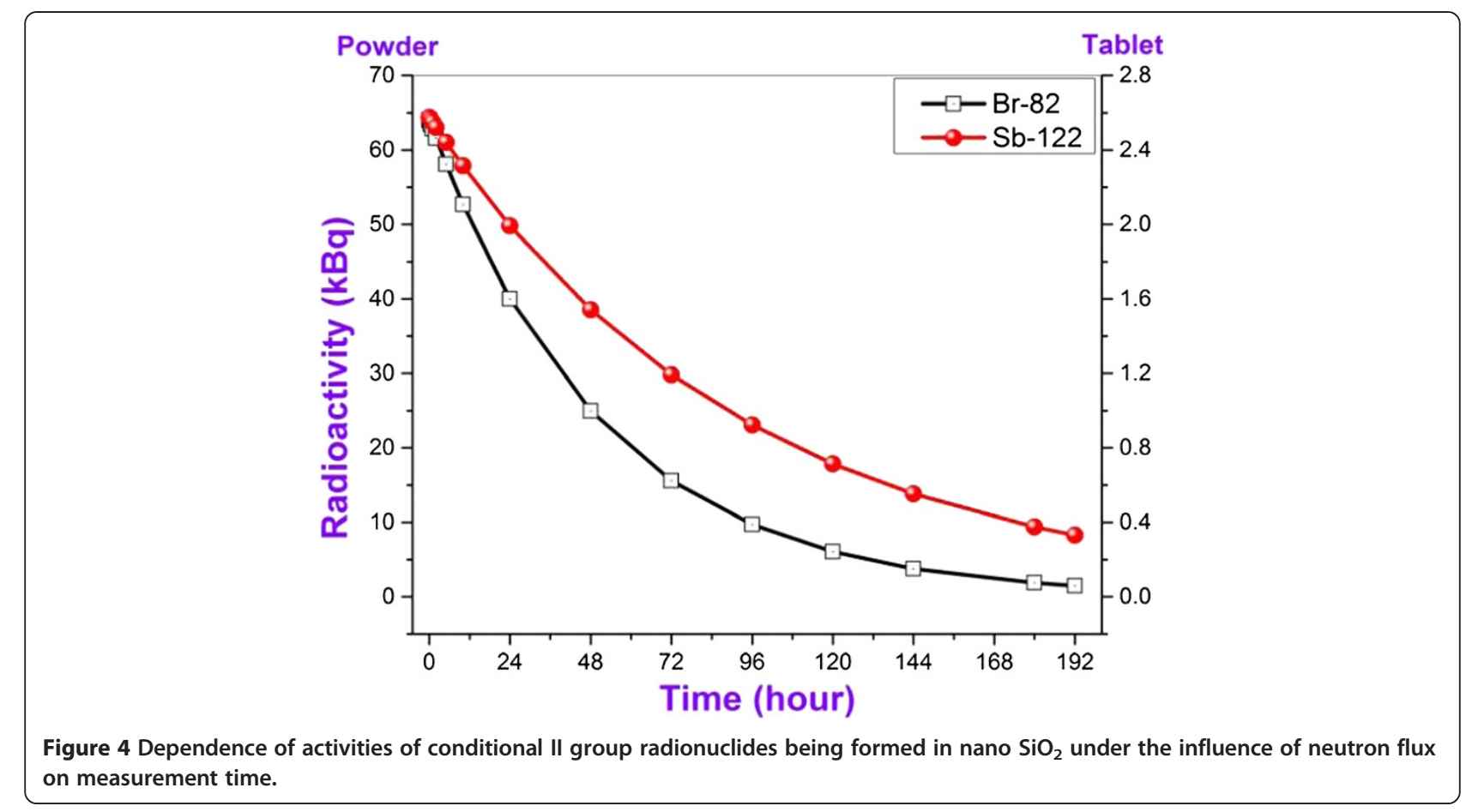

constant and which are relatively high within half decay, change little during experimental observation and it is expected the influence of their radioactive decay during subsequent study of nano $\mathrm{SiO}_{2}$ compound properties. According to comparison between activities of isotopes defined experimentally and activities of standards taken in the same condition and weight, it has been defined the amount of each element in the content of nano $\mathrm{SiO}_{2}$ compound [28]:

$$
C_{\text {sam }}=C_{s t} \frac{A_{\text {sam }}}{A_{s t}}
$$

here, $\mathrm{C}_{\mathrm{sam}}$ - concentration of the shown element isotope in nano $\mathrm{SiO}_{2}, \mathrm{C}_{\mathrm{st}}-$ concentration of comparison standard

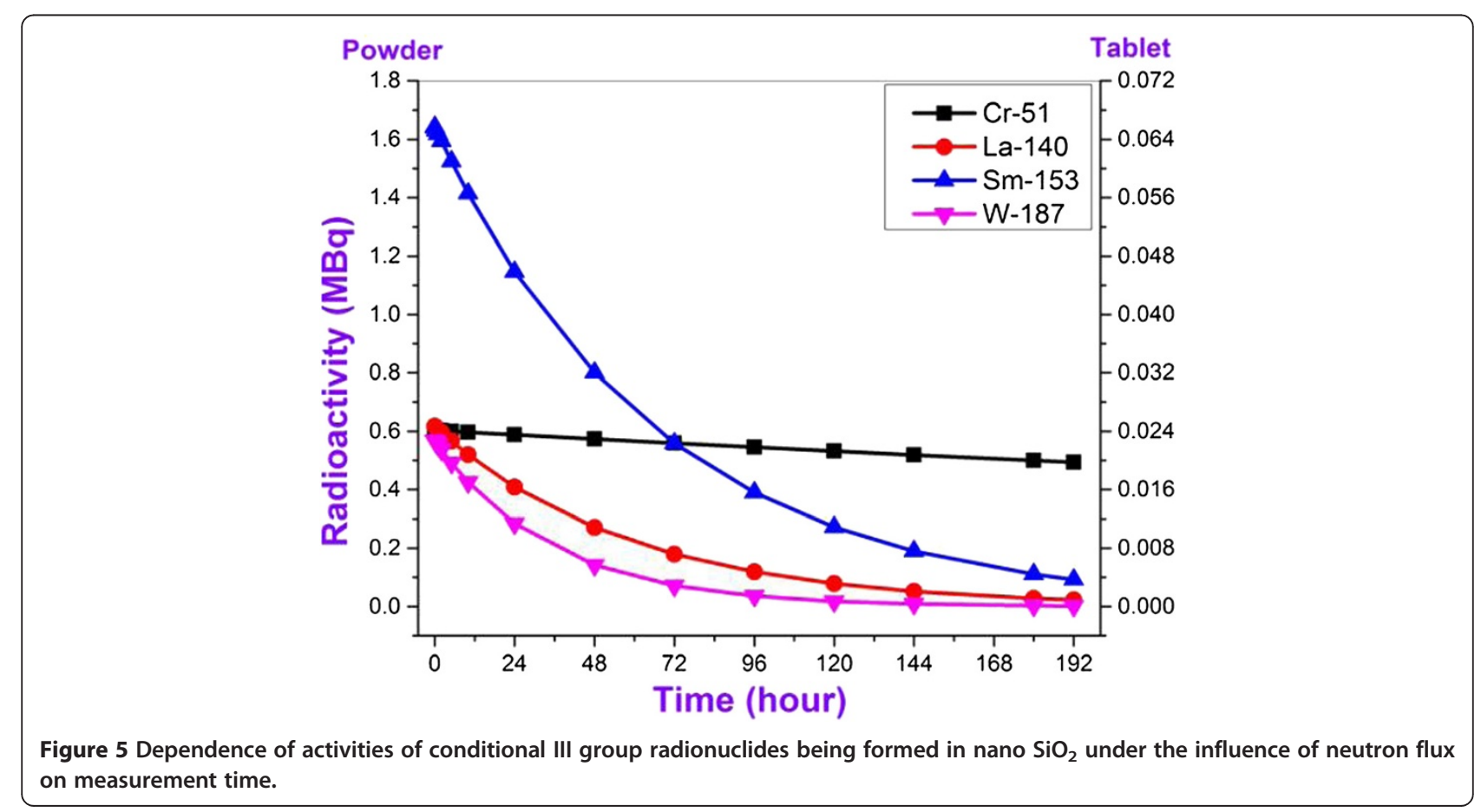




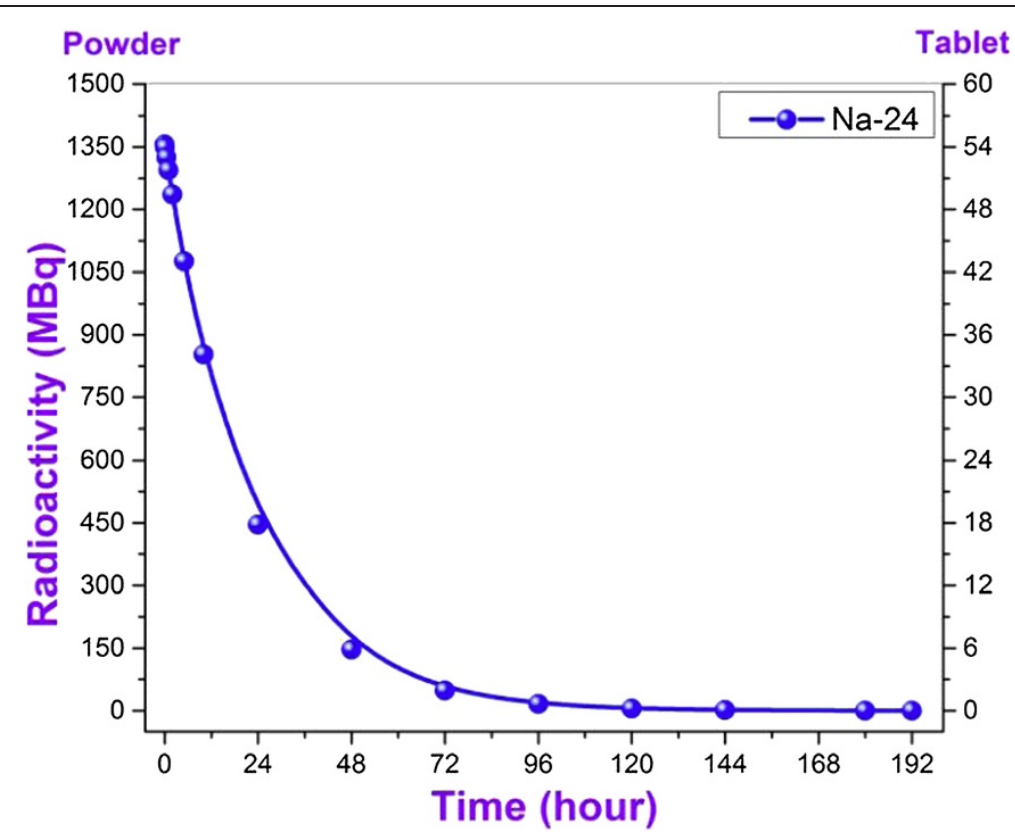

Figure 6 Dependence of activity of ${ }^{24} \mathrm{Na}$ isotope included to the conventional IV group originated in nano $\mathrm{SiO}_{2}$ under the influence of neutron flux on measurement time.

in the same isotope, $\mathrm{A}_{\text {sam }}$ and $\mathrm{A}_{\text {st }}$ are activities of sample and standard, respectively. If weights of sample and standards are different, the concentration of the element [28-31] is defined on the given technique. The obtained results have been given in Table 1 .

In general, it has been given in tables the different terms' radioactivity of radionuclides generated in $0,5 \%$

Table 1 Isotopes generated by neutron activation in nano $\mathrm{SiO}_{2}$, number of neutrons spent on activation of one isotope and number of isotopes in percent in sample

\begin{tabular}{llll}
\hline Stable isotope & Radioisotope & $\begin{array}{l}\text { Number of } \\
\text { capture neutron } \\
\text { in each nucleus }\end{array}$ & $\begin{array}{l}\text { Apx. amount } \\
\text { of blend (\%) }\end{array}$ \\
\hline Na-23 & Na-24 & +1 & $\sim 0,3 \%$ \\
\hline La-139 & La-140 & +1 & \\
Cr-50(52) & Cr-51 & +1 & $\sim 0,1 \%$ \\
Sm-150(152) & Sm-153 & +3 & \\
W-184(186) & W-187 & +3 & $<0,1 \%$ \\
\hline Sb-121 & Sb-122 & +1 & \\
Sb-123 & Sb-124 & +1 & $<0,1 \%$ \\
Br-81 & Br-82 & +1 & \\
\hline Fe-56(57,58) & Fe-59 & +3 & \\
Sc-45 & Sc-46 & +1 & \\
Sc-45 & Sc-47 & +2 & \\
Ta-181 & Ta-182 & +1 & \\
Hf-178(179,180) & Hf-181 & +3 & \\
Fe-54(n,p) & Mn-54 & +1 & \\
\hline
\end{tabular}

mixture during the influence of neutron flux to $99,5 \%$ purity nano $\mathrm{SiO}_{2}$, their initial isotopes and approximate amount. In Table 2 III and IV group radioisotopes and their activities have been shown with $\mathrm{MBq}$ and lined up in the form of initial activity increase.

Table 2 Conditional III and IV radioisotope groups generated in nano-compound under the influence of neutron flux

\begin{tabular}{llllll}
\hline Time (hour) & \multicolumn{5}{l}{ Radioactivity $(\mathbf{M B q})$} \\
\cline { 2 - 6 } & Na-24 & Sm-153 & La-140 & Cr-51 & W-187 \\
\hline 0 & $\sim 1355$ & $\sim 1.6$ & $\sim 0.62$ & $\sim 0.604$ & $\sim 0.568$ \\
0.1 & $\sim 1350$ & $\sim 1.6$ & $\sim 0.61$ & $\sim 0.603$ & $\sim 0.566$ \\
0.5 & $\sim 1325$ & $\sim 1.6$ & $\sim 0.61$ & $\sim 0.603$ & $\sim 0.56$ \\
1 & $\sim 1295$ & $\sim 1.6$ & $\sim 0.60$ & $\sim 0.602$ & $\sim 0.55$ \\
2 & $\sim 1235$ & $\sim 1.59$ & $\sim 0.59$ & $\sim 0.601$ & $\sim 0.53$ \\
5 & $\sim 1075$ & $\sim 1.52$ & $\sim 0.57$ & $\sim 0.6$ & $\sim 0.49$ \\
10 & $\sim 850$ & $\sim 1.41$ & $\sim 0.52$ & $\sim 0.59$ & $\sim 0.42$ \\
24 & $\sim 445$ & $\sim 1.14$ & $\sim 0.41$ & $\sim 0.58$ & $\sim 0.28$ \\
48 & $\sim 146$ & $\sim 0.8$ & $\sim 0.27$ & $\sim 0.57$ & $\sim 0.14$ \\
72 & $\sim 48$ & $\sim 0.55$ & $\sim 0.18$ & $\sim 0.56$ & $\sim 0.07$ \\
96 & $\sim 15$ & $\sim 0.38$ & $\sim 0.12$ & $\sim 0.55$ & $\sim 0.04$ \\
120 & $\sim 5$ & $\sim 0.27$ & $\sim 0.08$ & $\sim 0.53$ & $\sim 0.02$ \\
144 & $\sim 1.7$ & $\sim 0.19$ & $\sim 0.05$ & $\sim 0.52$ & $\sim 0.01$ \\
180 & $\sim 0.3$ & $\sim 0.11$ & $\sim 0.03$ & $\sim 0.5$ & $\sim 0.003$ \\
192 & $\sim 0.2$ & $\sim 0.09$ & $\sim 0.02$ & $\sim 0.49$ & $\sim 0.002$ \\
\hline
\end{tabular}


Table 3 Conditional I and II radioisotope groups generated in nano-compound under the influence of neutron flux

\begin{tabular}{|c|c|c|c|c|c|c|c|c|c|}
\hline \multirow[t]{2}{*}{ Time (hour) } & \multicolumn{9}{|c|}{ Radioactivity (kBq) } \\
\hline & Sb-122 & $\mathrm{Br}-82$ & Fe-59 & Sc-46 & Sc-47 & Ta-182 & Hf-181 & Mn-54 & Sb-124 \\
\hline 0 & $\sim 64.4$ & $\sim 64$ & $\sim 9.46$ & $\sim 8.25$ & $\sim 8.21$ & $\sim 3.67$ & $\sim 2.67$ & $\sim 1.86$ & $\sim 1.37$ \\
\hline 0.1 & $\sim 64.3$ & $\sim 63.9$ & $\sim 9.46$ & $\sim 8.25$ & $\sim 8.2$ & $\sim 3.67$ & $\sim 2.67$ & $\sim 1.86$ & $\sim 1.37$ \\
\hline 0.5 & $\sim 64.0$ & $\sim 63.44$ & $\sim 9.46$ & $\sim 8.25$ & $\sim 8.17$ & $\sim 3.66$ & $\sim 2.67$ & $\sim 1.86$ & $\sim 1.37$ \\
\hline 1 & $\sim 63.7$ & $\sim 62.8$ & $\sim 9.45$ & $\sim 8.25$ & $\sim 8.14$ & $\sim 3.66$ & $\sim 2.66$ & $\sim 1.86$ & $\sim 1.37$ \\
\hline 2 & $\sim 63$ & $\sim 61.6$ & $\sim 9.45$ & $\sim 8.24$ & $\sim 8$ & $\sim 3.65$ & $\sim 2.66$ & $\sim 1.86$ & $\sim 1.37$ \\
\hline 5 & $\sim 61$ & $\sim 58$ & $\sim 9.43$ & $\sim 8.24$ & $\sim 7.87$ & $\sim 3.65$ & $\sim 2.65$ & $\sim 1.85$ & $\sim 1.36$ \\
\hline 10 & $\sim 58$ & $\sim 53$ & $\sim 9.4$ & $\sim 8.23$ & $\sim 7.53$ & $\sim 3.65$ & $\sim 2.64$ & $\sim 1.85$ & $\sim 1.36$ \\
\hline 24 & $\sim 50$ & $\sim 40$ & $\sim 9.32$ & $\sim 8.19$ & $\sim 6.67$ & $\sim 3.64$ & $\sim 2.62$ & $\sim 1.85$ & $\sim 1.35$ \\
\hline 48 & $\sim 39$ & $\sim 25$ & $\sim 9.17$ & $\sim 8.12$ & $\sim 5.43$ & $\sim 3.62$ & $\sim 2.58$ & $\sim 1.85$ & $\sim 1.34$ \\
\hline 72 & $\sim 30$ & $\sim 15$ & $\sim 9$ & $\sim 8.05$ & $\sim 4.41$ & $\sim 3.6$ & $\sim 2.54$ & $\sim 1.84$ & $\sim 1.32$ \\
\hline 96 & $\sim 23$ & $\sim 10$ & $\sim 8.8$ & $\sim 7.98$ & $\sim 3.6$ & $\sim 3.57$ & $\sim 2.5$ & $\sim 1.84$ & $\sim 1.31$ \\
\hline 120 & $\sim 18$ & $\sim 6$ & $\sim 8.7$ & $\sim 7.92$ & $\sim 2.9$ & $\sim 3.55$ & $\sim 2.45$ & $\sim 1.84$ & $\sim 1.29$ \\
\hline 144 & $\sim 14$ & $\sim 4$ & $\sim 8.6$ & $\sim 7.85$ & $\sim 2.4$ & $\sim 3.53$ & $\sim 2.4$ & $\sim 1.83$ & $\sim 1.28$ \\
\hline 180 & $\sim 9$ & $\sim 2$ & $\sim 8.4$ & $\sim 7.75$ & $\sim 1.7$ & $\sim 3.5$ & $\sim 2.35$ & $\sim 1.82$ & $\sim 1.25$ \\
\hline 192 & $\sim 8$ & $\sim 1.5$ & $\sim 8.3$ & $\sim 7.72$ & $\sim 1.6$ & $\sim 3.48$ & $\sim 2.34$ & $\sim 1.82$ & $\sim 1.25$ \\
\hline
\end{tabular}

In Table 3 I and II group radioisotopes and their activities have been shown with $\mathrm{kBq}$ and lined up in the form of initial activity increase. It should be mentioned that radioisotopes of the elements $\mathrm{Si}$ and $\mathrm{O}$ which are the main part of the sample, which may arise, have a very small existence period and in our discussions they have not been considered. So, Si-31 has short decaytime $(\sim 2.5 \mathrm{~h})$ in $20 \mathrm{~h}$ irradiation, there could be produced some $\mathrm{P}$ which is beta emitter and cannot be detected by gamma detector. In general, in Table 1 it has been depicted initial isotopes and their amounts in percent according to blend radioisotopes generated under the influence of neutron flux.

\section{Conclusions}

It has been carried out identification of radioactivity appeared in nano $\mathrm{SiO}_{2}$ under the influence of neutron flux and isotopes that formed radioactivity. It has been revealed dependency of samples' activity and dose amount on irradiation time and sample dispersity. It has been defined that powdered nano $\mathrm{SiO}_{2}$ possess an activity approximately 25 times higher than the samples made as a tablet in special press form due to the interaction field with neutron to be big. Dependencies of radio activities of the revealed isotopes on observation time and amount of blend elements in percent have been defined. In the studied nano $\mathrm{SiO}_{2}$ samples it has been revealed the isotopes possessing relatively large half-decay time and these isotopes are suggested to be considered in explanation of physical properties of nano $\mathrm{SiO}_{2}$ compound within the period after irradiation.

\section{Competing interests}

The authors declare that they have no competing interests.

\section{Authors' contributions}

EH make all experiment and write first version of manuscript. AG participated in the sequence alignment and gave some idea. RM participated in drafted the manuscript. All authors read and approved the final manuscript.

\section{Acknowledgements}

The work has been carried out on the base of agreement signed between the Institute of Radiation Problems of ANAS and Jozef Stefan Institute of Slovenia. We express our gratitude to colleagues of the Institute of Radiation Problems of ANAS and "Reactor Infrastructure Centre (RIC)" and "Radiation Protection Unit" laboratories of Jozef Stefan Institute of Slovenia. We wish to thank Dr. Luka Snoj and Anze Jazbec for doing experiment with TRIGA Mark II type research reactor and fruitful discussions us.

Received: 26 April 2014 Accepted: 15 June 2014

Published online: 02 August 2014

\section{References}

1. SM Jafari, DA Bradley, CA Gouldstone, PHG Sharpe, A Alalawi, TJ Jordan, CH Clark, A Nisbet, NM Spyrou, Radiat. Phys. Chem. 97, 95-101 (2014)

2. AT Abdul Rahman, RP Hugtenburg, AIM Siti Fairus Abdul Sani, FI Alalawi, R Thomas, MA Barry, A Nisbet, DA Bradley, Appl. Radiat. Isot. 70,

$1436-1441$ (2012)

3. D Guarnieri, MA Malvindi, V Belli, PP Pompa, P Netti, J. Nanoparticle Res. 16, 2229 (2014)

4. P Buchwalter, J Rosé, B Lebeau, O Ersen, M Girleanu, P Rabu, P Braunstein, J-L Paillaud, J. Nanoparticle Res. 15, 2132 (2013)

5. Y Ding, X Chu, X Hong, P Zou, Y Liu, Appl. Phys. Lett. 100, 013701 (2012)

6. F Chi, L Yan, H Yan, B Jiang, H Lv, X Yuan, Opt. Lett. 37(9), 1406-1408 (2012) 
7. G Sponchia, R Marin, I Freris, M Marchiori, E Moretti, L Storaro, P Canton, A Lausi, A Benedetti, P Riello, J. Nanoparticle Res. 16, 2245 (2014)

8. M Martini, M Montagna, M Ou, O Tillement, S Roux, P Perriat, J. Appl. Phys. 106, 094304 (2009)

9. YP Timalsina, J Branen, DE Aston, K Noren, G Corti, R Schumacher, DN Mcllroy, J. Appl. Phys. 110, 014901 (2011)

10. T Bellunatoa, M Calvi, C Matteuzzi, M Musy, DL Perego, B Storaci, Eur. Phys. J. C 52, 759-764 (2007)

11. IA Rahman, P Vejayakumaran, J. Nanomater. 2012, 1-15 (2012). Article ID 132424

12. K Mohanraj, S Kannan, S Barathan, G Sivakumar, J. Optoelectron. Adv. M. 6(3-4), 394-397 (2012)

13. A Lazaro, G Quercia, HJH Brouwers, JW Geus, World J. Nanosci. Eng. 3, 41-51 (2013)

14. PL Barnes-Svarney, TE Svarney, "The Handy Geology Answer Book" (Visible Ink Press, Slovenia, 2004). ISBN 1578591562

15. M Martini, M Milazzo, M Piacentini, "Physics Methods in Archaeometry" Società Italiana di Fisica 154 (IOS Press, Italy, 2004). ISBN 1586034243

16. K Srivastava, N Shringi, V Devra, A Rani, Int. J. Innovative Research in Science, Engineering and Technology 2(7), 2936-2942 (2013)

17. EM Huseynov, AA Garibov, RN Mehdiyeva, Azerbaijan J. Phys. XIX(N1), 10-14 (2013). ISSN 1028-8546

18. RN Mehdiyeva, AA Garibov, EM Huseynov, Transactions of National Academy of Sciences of Azerbaijan, Series of Physics - Mathematical and Technical Sciences, Physics and Astronomy XXXII(N5), 83-88 (2012). ISSN 0002-3108

19. E Huseynov, A Garibov, R Mehdiyeva, Physica B. 450, 77-83 (2014)

20. L Snoj, G Zerovnik, A Trkov, Appl. Radiat. Isot. 70, 483-488 (2012)

21. L Snoj, A Trkov, R Jačimović, P Rogan, G Žerovnik, M Ravnik, Appl. Radiat. Isot. 69, 136-141 (2011)

22. L Snoj, A Kavcic, G Zerovnik, M Ravnik, Ann. Nucl. Energy 37(2), 223-229 (2010)

23. L Snoj, A Trkov, M Ravnik, G Zerovnik, Ann. Nucl. Energy 42, 71-79 (2012)

24. L Snoj, M Ravnik, Nucl. Eng. Des. 238(9), 2473-2479 (2008)

25. A Jazbec, G Zerovnik, L Snoj, A Trkov, Atw. Internationale Zeitschrift für Kernenergie 58(12), $701-705$ (2013)

26. V Radulović, Ž Štancar, L Snoj, A Trkov, Appl. Radiat. Isot. 84, 57-65 (2014)

27. G Zerovnik, M Podvratnik, L Snoj, Ann. Nucl. Energy 63, 126-128 (2014)

28. MV Frontasyeva, Physics of Elementary Particles and Atomic Nuclei 42(2), 636-718 (2011). ISSN 0367-2026

29. E Steinnes, "Some Neutron Activation Methods for the Determination of Minor and Trace Elements in Rocks" (Kjeller, Norway, 1972). 3 editions published

30. G Medkour Ishak-Boushaki, K Boukeffoussa, Z Idiri, M Allab, Appl. Radiat. Isot. 70(3), 515-519 (2012)

31. H Mommsen, J. Archaeol. Sci. 39(3), 704-707 (2012)

doi:10.1186/s40580-014-0021-7

Cite this article as: Huseynov et al: Study of blend composition of nano silica under the influence of neutron flux. Nano Convergence 2014 1:21.

\section{Submit your manuscript to a SpringerOpen ${ }^{\circ}$ journal and benefit from:}

- Convenient online submission

- Rigorous peer review

- Immediate publication on acceptance

- Open access: articles freely available online

- High visibility within the field

- Retaining the copyright to your article

Submit your next manuscript at $\gg$ springeropen.com 